\title{
Asociación de Enfermeras en Trasplantes A.C. (SEET)
}

Lic. Susana Nava Salgado* Lic. Minerva Medina Ponce** Lic. Clementina García Rivero*** Lic. Patricia Vergara Bautista**** Lic. Reyna Bertha Pardo Vásquez ${ }^{* * * *}$ EE. Enriqueta Ramírez Gómez ${ }^{* * * *}$ EE. Isabel Ibarra Blancas**** LE. Ma. de Lourdes Ramos Hernández ${ }^{* * * * *}$ EE. Agustina Hernández Mosco******

Vicepresidenta SEET* Vocal** Presidenta*** Vocales**** Tesorera***** Secretaria******

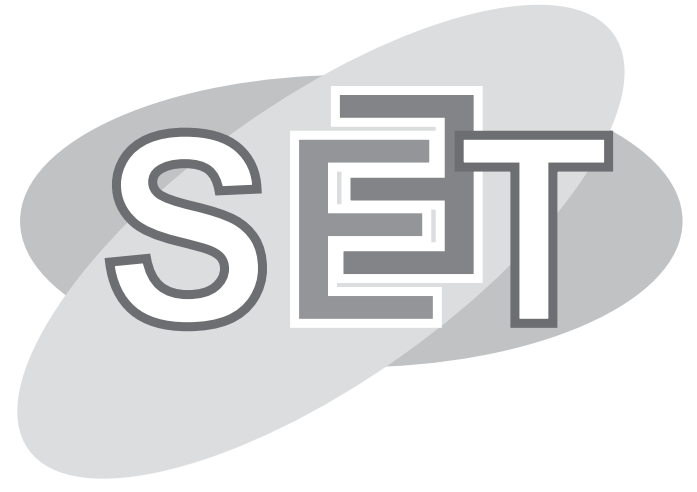

El campo de los trasplantes de órganos en humanos es uno de los más complejos y fascinantes de la medicina moderna y un capítulo brillante de la historia del siglo XX.

Los trasplantes de órganos y tejidos humanos, consisten en transferir un tejido u órgano, de su sitio original a otro diferente funcionando, esto puede ser dentro de un mismo individuo o bien de un individuo a otro, con el propósito de restaurar las funciones perdidas del mismo, sustituyéndolo por uno sano.

El personal de Enfermería es un eje importante en las instituciones donde se realizan transplantes ya que de ellas depende también el éxito del tratamiento y recuperación del paciente, su dedicación y el gran interés las motiva a proporcionar atención especializada a este tipo de pacientes y que con los avances de la medicina moderna caminan conjuntamente con el equipo multidisciplinario y enfrenta diariamente el contacto con el milagro de la vida y la medicina.

El 28 de junio del 2005 queda legalmente constituída la Asociación de Enfermeras en Trasplantes A. C., cuyo logo contiene las letras SEET. A partir de la fecha de constitución de la SEET, hasta la fecha, se cuenta con un número de 80 asociadas. El objetivo de la SEET es agrupar a todos los profesionistas que cuentan con cédula profesional expedida por la Dirección General de profesiones en la rama de Enfermería y que deseen pertenecer a la asociación.

La asociación proporciona capacitación al personal de Enfermería involucrado en la atención a pacientes trasplantados, con jugando la educación científica y la experiencia clínica. Adecuando el cuidado Enfermero a los recursos con que cuenta cada institución, promoviendo una actitud de aprendizaje permanente basada en la enseñanza continúa, combinando la teoría con la práctica buscando elevar permanentemente la calidad de atención al paciente trasplantado.

PALABRAS CLAVE : Trasplantes, órgano, asociación, Enfermería, rechazo, donación.

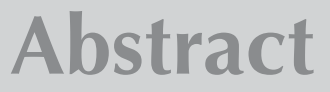

Human organ transplants is one of the most complex yet fascinating issues of modern medicine and a brilliant chapter of the 20th century history as well.

Human transplants mean replacing an organ or tissue with a healthy one in order to restore lost biological functions in an individual. 
Because of their multidisciplinary and specialized attention, treatment and recovery of patients, nursing staff represent a critical support to the transplant-related institutions. They necessarily face the everyday miracle of life and medicine.

On june the 28th, 2005 the Nursing in Transplants Association (SEET) is legaly constituted. Currently gathering 80 members, by merging scientific education and clinical experience its objective is to orient and train nurses, holding the "cedula" of the General Direction of Professions, in the proper transplant procedures, thus promoting a continuous field-update attitude.

KEY WORDS: Transplants, organ, association, nursing, rejection, donation.

\section{TRASPLANTES DE ÓRGANOS Y TEJIDOS.}

El campo de los trasplantes de órganos en humanos es uno de los más complejos y fascinantes de la medicina moderna y un capítulo brillante de la historia del siglo XX.

Los trasplantes de órganos y tejidos humanos, consisten en transferir un tejido u órgano, de su sitio original a otro diferente funcionando, esto puede ser dentro de un mismo individuo o bien de un individuo a otro, con el propósito de restaurar las funciones perdidas del mismo, sustituyéndolo por uno sano.

Hay distintos tipos, dependiendo de la relación genética entre el donador y el receptor de un trasplante:

- Autotrasplantes o autoinjertos. Se utiliza el tejido del propio individuo, es decir, donador y receptor son la misma persona.

- Isotrasplantes. Entre gemelos idénticos o univitelinos, es decir, cuando donador y receptor son genéticamente idénticos.

- Homotrasplantes o alotrasplantes. Donador y receptor pertenecen a la misma especie, pero genéticamente son diferentes.

- Heterotrasplantes o xenotrasplantes. Entre sujetos de diferentes especies, o con órganos artificiales ${ }^{1}$.

La persona que recibe los beneficios del trasplante, se denomina receptor, ya que recibe un órgano, tejido, células o productos en su organismo para realizar la misma función que realizaban en el donador.

\section{ANTECEDENTES}

- En 1954 se realizó el primer trasplante renal exitoso en humanos en Boston, USA.
- En 1963 Hardy realizó el primer trasplante pulmonar y Starzl el primer trasplante hepático.

- En 1967, Barnard efectuó el primer trasplante de corazón en Sudáfrica².

El objetivo fundamental de los trasplantes de órganos es salvar vidas y proporcionar una rehabilitación significativa tanto física como social de los pacientes, reintegrándolos a la familia y al trabajo con una mejor calidad de vida.

\section{Problemas de rechazo}

En la medida en que mejoran las técnicas quirúrgicas y se superan los problemas del rechazo, el trasplante de órganos se hace cada vez más imprescindible para salvar la vida de los miles de enfermos que de otro modo están condenados a perecer.

Los órganos para trasplante se obtienen de donantes. Los donantes pueden ser vivos o cadavéricos. Los donantes vivos, preferentemente emparentados, pueden donar a sus seres queridos uno de sus riñones, parte de sus pulmones, una parte del hígado o un segmento del páncreas. Lo más importante cuando se cuenta con un donante vivo, es que la donación sea voluntaria y que el donante entienda el riesgo de la donación.

\section{Muerte cerebral}

En la década del 50 y a comienzos de los años sesenta en que se comprendió el concepto de muerte cerebral y se aceptó que era equivalente a la muerte del individuo, solo se transplantaban riñones (que son órganos pares) procedentes de donantes vivos.

\section{Donantes}

Así los donantes cadavéricos, pero solamente en un estado de muerte cerebral, pueden donar el corazón, ambos 
riñones, el hígado, los dos pulmones, el intestino delgado y el páncreas, beneficiando de este modo a por lo menos 7 pacientes condenados de otro modo a perecer.

Los pacientes en muerte cerebral o encefálica son los únicos posibles donantes de órganos, debido a que todos los órganos transplantables (riñones, corazón, pulmones, hígado, páncreas, intestino delgado) necesitan ser retirados del cuerpo con el tiempo mínimo de isquemia (tiempo durante el cual no están irrigados por la circulación normal) para que no se deterioren.

Cuando se realizan trasplantes con los órganos de un donante en estado de muerte cerebral, la actitud de respeto con la vida humana no desaparece. Al contrario, el respeto por el cuerpo del donante, se ve superado por otro superior, que es el respeto a la vida de quienes esperan el trasplante para poder salvarse. Por lo tanto, la actitud más adecuada por parte de los familiares de un potencial donante, a quien sus órganos ya no le sirven, es ofrecerlos a quienes los necesitan.

El trasplante de órganos y tejidos, tales como córneas, corazón, hígado y riñones, entre otros, es considerado como la única técnica para el tratamiento de enfermedades terminales e irreversibles de esos órganos.

\section{Un regalo de vida}

Un órgano donado cuando se trasplanta con éxito constituye UN REGALO DE VIDA. Por lo tanto, en ningún caso existe una compensación económica al donante o a sus familiares por la donación ni se exige a los pacientes receptores precio alguno por el órgano trasplantado. La donación es una entrega de sí mismo y no puede medirse con dinero. Por lo tanto, la parte de la persona que se entrega como donación no puede tener valor de mercado. $\mathrm{Ni}$ el cuerpo humano ni ninguna de sus partes puede ser objeto de compra venta. ${ }^{3}$

El trasplante de órganos en el momento actual es la mejor alternativa de tratamiento y en muchos casos la única, para la falla terminal e irreversible de muchos órganos vitales como el corazón, el hígado o los riñones.

Para que con el trasplante se puedan salvar vidas humanas se necesitan órganos y para tener órganos se necesitan donantes. Sin órganos no hay trasplantes y sin donantes no hay órganos.

Teniendo en cuenta que "La donación de órganos es un acto de solidaridad y fraternidad humana y una prueba de que el cuerpo muere pero jamás el amor que lo sostiene", todas las grandes religiones de la civilización apoyan la práctica de los trasplantes y la donación de órganos.

A pesar de estos esfuerzos mancomunados, sin embargo, la tasa de donantes se mantiene estancada y el número de pacientes condenados a morir por falta de un órgano es cada vez mayor.

\section{TRASPLANTES EN MÉXICO}

En 1963 los Doctores Federico Ortiz Quesada, Manuel Quijano Narezo y Manuel Flores Izquierdo, realizaron el primer trasplante renal en el entonces Centro Médico Nacional que actualmente es El Siglo XXI, del Instituto Mexicano del Seguro Social (IMSS). Cuatro años más tarde se realizaron trasplantes en el Instituto Nacional de la Nutrición de la Secretaría de Salud (SSA), el Hospital Central Militar y el Instituto de Seguridad Social al Servicio de los Trabajadores del Estado (ISSSTE). ${ }^{4}$

En la década de los ochenta México creció a pasos gigantes en materia de trasplantes. En 1985 médicos mexicanos realizaron el primer trasplante de hígado, y en 1987 se realizó el trasplante de páncreas. Pero sin duda el avance más significativo en esta materia fue en 1988, cuando en el Hospital de Especialidades del Centro Médico La Raza del IMSS, el doctor Rubén Argüero realizó el primer trasplante de corazón y en 1989 efectuaron en el Instituto Nacional de Enfermedades Respiratorias de la SSA, el primer trasplante de pulmón.

\section{MARCO JURÍDICO}

Durante los primeros años en que se realizaron trasplantes en México se carecía de un marco jurídico que reglamentara este tipo de intervenciones. Por ello en 1973 su regulación quedó respaldada a través del Código Sanitario Federal. Y en 1976 se estableció el Registro Nacional de Trasplantes constituído, hasta la fecha, como órgano responsable de vigilar el apego a la normatividad, la expedición de licencias sanitarias para el funcionamiento de bancos de órganos y tejidos, la autorización para el internamiento o salida de los mismos, así como de contabilizar los trasplantes realizados y de llevar el registro de los pacientes en espera de órganos trasplantados. Posteriormente en 1984, se establece la Ley General de Salud, que en su Título Decimocuarto regula el control sanitario sobre la disposición de órganos, tejidos, células y cadáveres de seres humanos. De esa manera, también quedó estipulado que estas tareas son competencia de la SSA. ${ }^{5}$ 
En 1999 se creó el Consejo Nacional de Transplantes (Conatra), a consecuencia de la gran demanda de órganos y tejidos que se registran anualmente en México. Desde que se empezó a realizar transplantes en nuestro país se han llevado a cabo más de 30 mil de estas cirugías, principalmente de hígado, riñones, corazón, córneas y piel.

\section{Necesidad de donadores}

Desde el momento en que se ha reconocido a la muerte encefálica como la muerte de la persona y desde que se iniciaron los programas de trasplante con donantes cadavéricos, se ha insistido en que la donación debe ser anónima, altruista, solidaria, por amor al prójimo y sin que por ella exista ningún tipo de retribución económica. Para lograr la realización de los trasplantes con donantes cadavéricos, se requiere sin embargo, un alto grado de sensibilización y conocimiento por parte de la población de los resultados perseguidos y logrados con el trasplante de órganos y la aceptación de que la muerte encefálica es la muerte de la persona. Esto se consigue únicamente gracias al concurso mancomunado de la sociedad en su conjunto y muy especialmente del estado, de la prensa, de los educadores, de la Iglesia y de las sociedades médicas. ${ }^{6}$

Una persona puede, por su deseo de hacer el bien a un enfermo, expresar su voluntad en vida, sea verbalmente o por escrito, en un carnet u otro documento, de donar alguno de sus órganos para después de la muerte. Esta decisión de donar debería ser siempre respetada por sus familiares y amigos. Por otra parte, si en vida el paciente no manifestó su deseo de ser donador, los familiares próximos, que son quienes mejor le conocen, son las personas más indicadas para informar acerca de sus sentimientos al respecto.

\section{LEY GENERAL DE SALUD}

Para ser donador vivo, la Ley General de Salud establece lo siguiente:

Artículo 333.- Para realizar trasplantes entre vivos, deberán cumplirse los siguientes requisitos respecto del donante:

I. Ser mayor de edad y estar en pleno uso de sus facultades mentales;

II. Donar un órgano o parte de él que al ser extraído su función pueda ser compensada por el organismo del donante de forma adecuada y suficientemente segura;

III. Tener compatibilidad aceptable con el receptor;

IV. Recibir información completa sobre los riesgos de la operación y las consecuencias de la extracción del órgano o tejido, por un médico distinto de los que intervendrán en el trasplante;

V. Haber otorgado su consentimiento en forma expresa, en términos del artículo 322 de esta Ley, y

VI.- Los trasplantes se realizarán, de preferencia, entre personas que tengan parentesco por consanguinidad, civil o de afinidad. Sin embargo, cuando no exista un donador relacionado por algún tipo de parentesco, será posible realizar una donación, siempre y cuando se cumpla con los siguientes requisitos:

a) Obtener resolución favorable del Comité de Trasplantes de la institución hospitalaria, donde se vaya

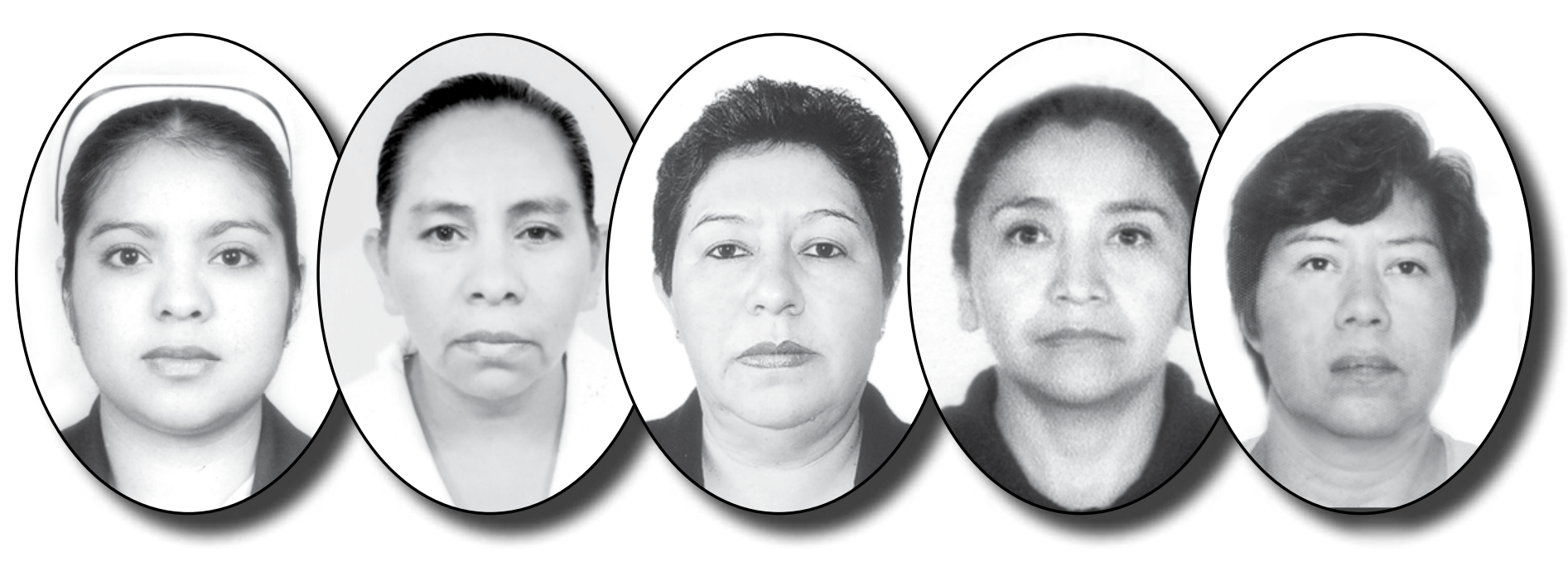

MESA DIRECTIVA DE LA SEET 
a realizar el trasplante, previa evaluación médica, clínica y psicológica;

b) El interesado en donar deberá otorgar su consentimiento expreso ante Notario Público y en ejercicio del derecho que le concede la presente Ley, manifestando que ha recibido información completa sobre el procedimiento por médicos autorizados, así como precisar que el consentimiento es altruista, libre, consciente y sin que medie remuneración alguna. El consentimiento del donante para los trasplantes entre vivos podrá ser revocable en cualquier momento previo al trasplante, y

c) Haber cumplido todos los requisitos legales y procedimientos establecidos por la Secretaría, para comprobar que no se está lucrando con esta práctica. $^{7}$

\section{Intervención de Enfermería}

Las Enfermeras que cada día están cerca de las personas que requieren de algún tipo de trasplante y que de alguna manera viven junto con ellas, paso a paso, el proceso tan complejo de donación y trasplante, tomaron la desición de integrar una Asociación de ayuda y sobretodo de enseñanza para todo el profesional de Enfermería.

Se sabe que en cualquier ámbito de trabajo y aún más en la vida social de México, las Enfermeras se enfrentan en varias ocasiones a responder ante las necesidades de asesoria sobre donación y trasplante de la población mexicana y del mismo gremio de Enfermeras.

El personal de Enfermería es un eje importante en las instituciones donde se realizan transplantes ya que de ellas depende también el éxito del tratamiento y recuperación del paciente, su dedicación y el gran interés las motiva a proporcionar atención especializada a este tipo de pacientes y que con los avances de la medicina moderna caminan conjuntamente con el equipo multidisciplinario y enfrenta diariamente el contacto con el milagro de la vida y la medicina

Así es como un grupo de Enfermeras especializadas de diferentes instituciones: HIMFG, IMSS, ISSSTE, y MEDICA SUR, se reunieron en una asociación creada por Enfermeras para Enfermeras interesadas en conocer todo lo relacionado con los transplantes: LA SEET.

\section{ANTECEDENTES DE LA SEET}

En el año del 2003, ante el proyecto de un congreso internacional de hemato-oncología, se reúne un grupo de Enfermeras especializadas en la atención del paciente trasplantado, este grupo estaba integrado por Enfermeras de las siguientes instituciones: HIMFG, IMSS, ISSSTE, y MEDICA SUR. Su finalidad era convocar a las Enfermeras involucradas en la atención del donador o receptor de trasplante, para la estandarización de los cuidados enfermeros en las diversas instituciones de salud pública o privada ${ }^{8}$.

Se realiza un investigación en el país sobre grupos de Enfermeras dedicadas al desarrollo del cuidado enfermero del paciente trasplantado, cuyos resultados fueron la carencia de un grupo de Enfermeras dedicas a este objetivo. En el 2004 se conforma la Asociación de Enfermeras En Trasplantes, integrada por Enfermeras de diversas instituciones públicas y privadas. El 28 de junio del 2005 queda legalmente constituída la Asociación de Enfermeras En Trasplantes A. C., cuyo logo contiene las letras SEET. A partir de la fecha de constitución de la SEET, hasta la fecha, se cuenta con un total de 80 asociadas.

\section{OBJETIVOS}

El objetivo de la seet es: Agrupar a todos los profesionistas que cuentan con cédula profesional expedida por la Dirección General de profesiones en la rama de Enfermería y que deseen pertenecer a la asociación.

\section{Específicos}

- Promover la impartición de cursos de actualización en relación a los trasplantes de órganos.

- Difundir por cualquier medio permitido por la ley los avances que se tengan en relaciona los trasplantes ya se en forma individual o colectiva.

- Elaborar en coordinación con alguna institución educativa superior planes de estudio de alguna especialización en la materia a la que pertenece la asociación.

- Impulsar la investigación científica y tecnológica dentro del ámbito de la rama profesional de Enfermería.

- Organizar y fomentar toda actividad social que favorezca directa o indirectamente los objetivos de esta asociación, asociarse o colaborar con otras asociaciones o instituciones públicas o privadas que tengan objeto similar al de esta asociación.

- Actualizar al personal de Enfermería acerca de los avances científicos relacionados con los transplantes. ${ }^{9}$ 


\section{SOCIOS}

\section{Requisitos para pertenecer a la SEET:}

- Acreditar debidamente tener titulo de Enfermera, para lo cual deberá acompañar su solicitud de ingreso, copia certificada de su titulo profesional así como de la cedula profesional correspondiente.

- $\quad$ No haber sido sancionado por violación a cualquier disposición legal contenida en la ley reglamentaria del articulo quinto constitucional,

- Cubrir la cuota que determine para tal efecto la asamblea general ordinaria de asociados a propuesta del consejo directivo.

- Haber sido admitido por la asamblea de asociados para formar parte de la asociación.

\section{DERECHOS DE LOS ASOCIADOS}

- Elegir y ser electo para cualquier puesto de representación del consejo directivo siempre y cuando haya asistido al noventa por ciento de las asambleas.

- $\quad$ Tener voz y voto en las asambleas generales ordinarias y extraordinarias de asociados que convoquen, en el concepto de que cada asociado tendrá derecho a un voto.

- Solicitar la revisión de libros, los registros contables y en general la información necesaria sobre el funcionamiento y actividades de los componentes del consejo directivo.

- Ejercer el derecho de petición y crítica así como denunciar las irregularidades que se adviertan entre los miembros representativos de la asociación.

- Solicitar becas en cursos de actualización en México o en el extranjero que sea relacionado con trasplantes.

\section{OBLIGACIONES DE LOS ASOCIADOS}

- Cumplir y hacer cumplir los estatutos y acatar los acuerdos y reglamentos internos emanados en ala asambleas así como los acuerdos del consejo directivo.

- Concurrir a las asambleas que se convoquen.
- Contribuir al sostenimiento de los gastos de la asociación.

- Notificar cualquier decisión personal que afecte a la asociación.

- No realizar acto alguno que entorpezca las labores de la asociación o que lesione el prestigio o el patrimonio de la misma.

- Respetar y cumplir las normas contenidas en el código de ética de la asociación debidamente aprobado por la asamblea general de los asociados.

- $\quad$ Separarse de la asociación mediante aviso dirigido al consejo directivo, cuando menos con dos meses de anticipación a la fecha en que la separación surta efecto. ${ }^{10}$

\section{MESA DIRECTIVA}

Lic. Clementina García Rivero.

Presidenta

Lic. Susana Nava Salgado

Vicepresidenta

Enf. Agustina Hernández Mosco

Secretaria

Lic. Ma. de Lourdes Ramos Hernández.

Tesorera

Lic. Enfermera Patricia Vergara Bautista

Vocal

Enf. Enriqueta Ramírez Gómez

Vocal

Lic. Minerva Medina Ponce

Vocal

Enf. Isabel Ibarra Blancas

Vocal

Lic. Reyna Bertha Pardo Vásquez

Vocal

\section{MISIÓN}

La Asociación de Enfermeras en Trasplantes, proporciona capacitación al personal de Enfermería involucrado en la atención a pacientes trasplantados, conjugando la educación científica y la experiencia clínica. Adecuando el cuidado enfermero a los recursos con que cuenta cada 
institución, promoviendo una actitud de aprendizaje permanente basada en la enseñanza continúa, combinando la teoría con la práctica buscando elevar permanentemente la calidad de atención al paciente trasplantado.

\section{VISIÓN}

La SEET es reconocida por su participación, como lideres altamente capacitados, dentro de la educación de Enfermería al contar con estrategias de trabajo que favorecen la atención del paciente trasplantado basada en valores de honestidad, equidad y lealtad, distinguiéndose como un equipo de alto rendimiento con reconocimiento a nivel nacional.

\section{DIRECCIÓN}

Tuxpan \#8. Despacho 301. Col. Roma Sur. CP. 06760. Tel. 55847107

\section{CONGRESOS Y EVENTOS REALIZADOS}

\begin{tabular}{|l|l|l|}
\hline \multirow{2}{*}{ FECHA } & \multicolumn{1}{|c|}{ EVENTO } & \multicolumn{1}{c|}{ LUGAR } \\
\hline $\begin{array}{l}\text { Enero } \\
2005\end{array}$ & $\begin{array}{l}\text { Presentación de la } \\
\text { Asociación de Enfermeras } \\
\text { en Trasplantes }\end{array}$ & México, D.F. \\
\hline $\begin{array}{l}\text { Julio } 2005 \\
\text { 1er. Congreso "Avances y } \\
\text { Actualidades de Enfermería } \\
\text { en Trasplantes" }\end{array}$ & CMN Siglo XXI \\
\hline 2006 & $\begin{array}{l}\text { Taller de Líneas } \\
\text { Intravasculares }\end{array}$ & $\begin{array}{l}\text { Universidad } \\
\text { Obrera de } \\
\text { México }\end{array}$ \\
\hline
\end{tabular}

\section{REFERENCIAS BIBLIOGRAFICAS.}

1 Centro Nacional de Trasplantes. Trasplantes. Documento fotocopiado. México, 2006. pág. 1.

2 Consejo Estatal de Trasplantes Guanajuato. Historia y estado actual de los trasplantes en Guanajuato. Documento fotocopiado. México, 2006. pág. 1.

3 Centro Nacional de Trasplantes. Op cit p.4

4 Centro Nacional de Trasplantes. Historia de los Trasplantes en México. Documento fotocopiado. México, 2006. pág. 1.

5 Televisión Azteca. Trasplantes en México: antecedentes. Documento fotocopiado. México, 2006, p.2.

6 Centro Nacional de Trasplantes. Historia de los Trasplantes en México. Op cit p.2.

7 Id.

8 Susana Nava Salgado. Antecedentes de la Asociación de Enfermeras en Trasplantes. Documento impreso. México, 2006, p.2.

9 Asociación de Enfermeras en Trasplantes. Estatutos de la Asociación. Documento impreso. México, 2005. p. 2.

10 Ibíd. p.5.

11 Asociación de Enfermeras en Trasplantes. Misión y visión. México, 2004, p. 2.

\section{DIRECCIÓN PARA CORRESPONDENCIA}

Susana Nava Salgado: susynavas@yahoo.com.mx susynavas_uaq@yahoo.com.mx Clementina García Rivero: clegari57@ yahoo.com.mx

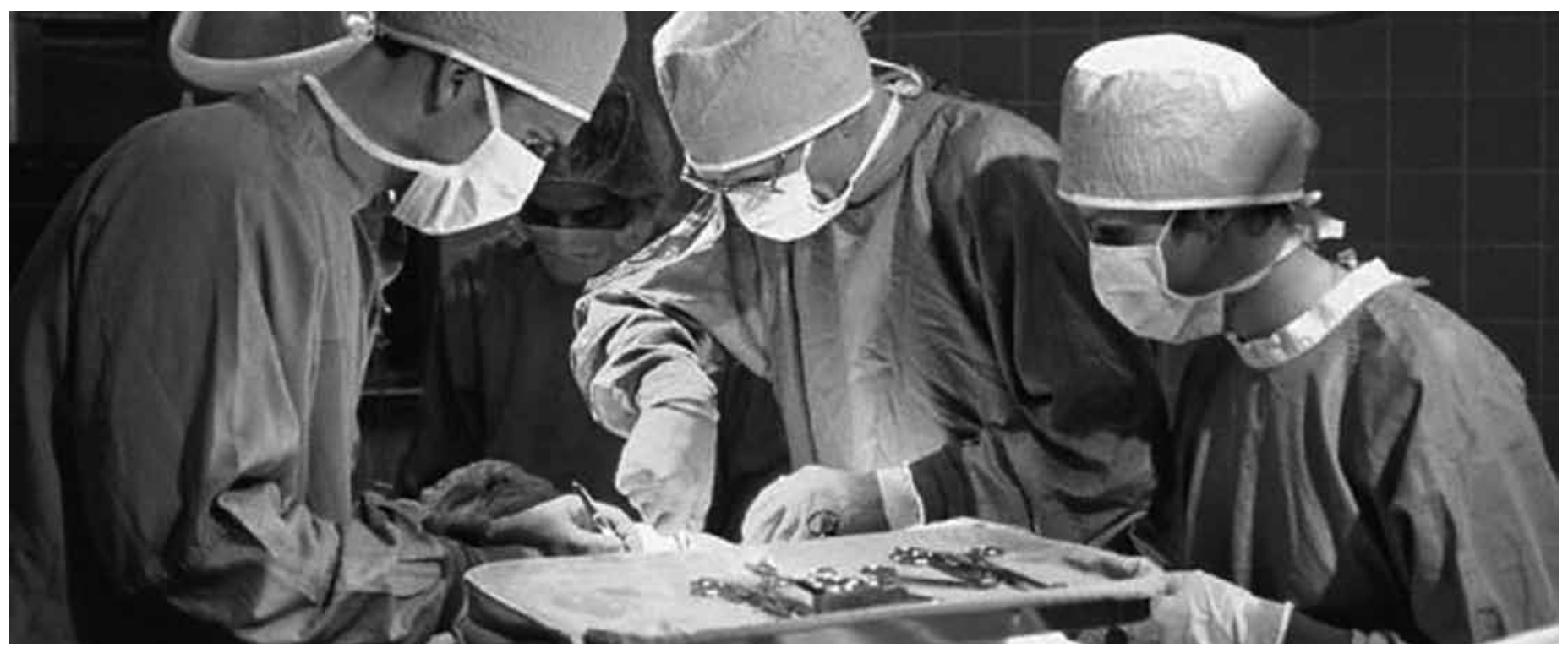

